\title{
The effect of 3-bromopyruvate on the properties of cathepsin B in the aspect of metastatic potential of colon cancer cells
}

\author{
Izabela Szczuka ${ }^{A-F}$, Jerzy Wiśniewski ${ }^{B, C}$, Irena Kustrzeba-Wójcicka ${ }^{\mathrm{E}, \mathrm{F}}$, Grzegorz Terlecki ${ }^{\mathrm{A}, \mathrm{C}-\mathrm{F}}$ \\ Department of Medical Biochemistry, Wroclaw Medical University, Poland \\ A - research concept and design; $B$ - collection and/or assembly of data; $C$ - data analysis and interpretation; \\ $D$ - writing the article; $E$ - critical revision of the article; $F$ - final approval of the article
}

Address for correspondence

Izabela Szczuka

E-mail: izabela.szczuka@umed.wroc.pl

\section{Funding sources \\ None declared}

Conflict of interest

None declared

\section{Acknowledgements}

The authors would like to thank the Foundation of Wroclaw Medical University (FUM) and its Board Chairmen for financing the purchase of HCT 116 cell line.

Received on April 28, 2020

Reviewed on May 24, 2020

Accepted on June 7, 2020

Published online on August 21, 2020

\section{Cite as}

Szczuka I, Wiśniewski J, Kustrzeba-Wójcicka I, Terlecki G.

The effect of 3-bromopyruvate on the properties

of cathepsin B in the aspect of metastatic potential of colon cancer cells. Adv Clin Exp Med. 2020;29(8):949-957. doi:10.17219/acem/123622

DOI

10.17219/acem/123622

Copyright

Copyright by Author(s)

This is an article distributed under the terms of the

Creative Commons Attribution 3.0 Unported (CC BY 3.0)

(https://creativecommons.org/licenses/by/3.0/)

\begin{abstract}
Background. Cathepsin B (CTSB, EC 3.4.22.1) is a protease that physiologically resides in lysosomes and whose biosynthesis, cell surface location, intracellular distribution, and enzymatic activity undergo changes during the pathogenesis of cancer; it plays an important role in metastasis. Due to its active center structure, it is theoretically susceptible to the action of 3-bromopyruvate - an analogue of pyruvic acid and an alkylator that has been studied in depth in recent years for its anti-cancer activity, mainly through the inhibition of glycolytic enzymes.

Objectives. To investigate the effects of 3-bromopyruvate on the tumor cell properties in selected colorectal carcinoma cell lines that are widely attributed to the dysregulation of CTSB. Moreover, the effect of direct action of 3-bromopyruvate on the CTSB molecule was investigated in vitro.

Material and methods. The research on the effect of 3-bromopyruvate on Caco-2/HCT 116 cells and purified human CTSB included a scratch/wound healing assay, a cell invasion assay, spectrofluorimetric measurements of enzymatic activity of cathepsin B, indirect immunofluorescence and flow cytometry, zymography, and liquid chromatography/mass spectrometry methods.

Results. 3-bromopyruvate reduced the activity and secretion of active CTSB and lowered the motility and invasiveness of Caco-2/HCT 116 human colorectal cancer cells. It decreased the exposure of CTSB on the outer surface of the cell membrane in both cell lines. 3-bromopyruvate inhibited the activity of CTSB reversibly and did not alkylate the molecule of the enzyme.

Conclusions. This is the first report on the effect of 3-bromopyruvate directly on CTSB and indirectly on the mechanisms leading to its distinct pathophysiological properties, resulting in increased metastatic potential of cancer cells, among others. Although detailed mechanisms of the interaction between 3-bromopyruvate and the active site of CTSB require further research, the results provide a new perspective from which to study the antitumor effect of 3-bromopyruvate.
\end{abstract}

Key words: cathepsin B, protease inhibitor, 3-bromopyruvate, Caco-2 cells, HCT 116 cells 


\section{Introduction}

Cathepsin B (CTSB; EC 3.4.22.1) is a cysteine protease physiologically occurring within the lysosomes of eukaryotic cells. Under physiological conditions it is controlled on many levels, including through the activation of zymogen or the action of endogenous inhibitors. ${ }^{1}$ It is extensively studied due to its role in cancer pathogenesis and metastasis, when its biosynthesis, intracellular distribution, location on the cell surface, and enzyme activity are altered. ${ }^{2,3}$ This enzyme plays an important role in the metastasis process by directly degrading extracellular matrix (ECM) proteins (such as fibrinogen, type IV collagen and laminin ${ }^{4}$ ) and intensifying the proteolytic cascade by inactivating the tissue inhibitors of metalloproteinases (TIMP). ${ }^{5}$ The mechanism of CTSB enzymatic catalysis is based on the interaction of 3 amino acid residues within the active center of the enzyme (forming the catalytic triad): Cys29, His199 and Asn219. ${ }^{6}$ Altered levels of CTSB expression and activity, as well as different locations and distribution, are related to the occurrence of various pathological conditions, particularly neoplastic diseases, ${ }^{7}$ neurodegenerative diseases ${ }^{8}$ and inflammatory diseases of the nervous system. ${ }^{9}$ Mitrović et al. proved that the suppression of endo- and exopeptidase activity of CTSB limits ECM degradation and the invasiveness of tumor cells. ${ }^{10}$ The role of CTSB in pre-cancer processes and the development, metastasis and invasiveness ${ }^{11-13}$ of colon cancer cells has also been demonstrated. It was found that an elevated level of CTSB correlates positively with the increased mortality of patients with colon cancer. ${ }^{14}$ Higher immunoreactivity of this protein has also been found in cancerous tissues and elevated concentrations have been found in the urine and serum of patients with metastatic changes. ${ }^{15,16}$ Van Noorden et al. demonstrated in a rat model that the selective inhibition of CTSB reduces the probability of metastases occurring from the colon to the liver. ${ }^{17}$

Many inhibitors of CTSB have already been discovered or synthesized, with different types and modes of inhibition, selectivity or reversibility of the reaction. ${ }^{18}$ Although some of them were promising, the possibilities of conducting research in clinical practice with these compounds turned out to be very limited. The compound tested in this study for the inhibition of CTSB was 3-bromopyruvate (3-BrPA). It is a synthetic, structural analogue of pyruvic and lactic acids, entering eukaryotic cells through MCT1 monocarboxylic acid transporters. ${ }^{19}$ It is intensively studied because it is thought to have an antitumor effect, mainly via alkylation of key glycolytic enzymes in tumor cells. ${ }^{20,21}$ To date, 2 cases of clinically applying this compound in the treatment of advanced cancers have been reported. ${ }^{22,23}$ Studies on the effect of 3-BrPA on CTSB have not yet been conducted, so this is the first attempt in the literature to explore this subject.

\section{Material and methods}

\section{Material}

3-bromopyruvate (purity $\geq 97 \%$ ) was purchased from Sigma-Aldrich (St. Louis, USA). Human liver CTSB (purity $\geq 95 \%$ by SDS-PAGE) was obtained from Calbiochem (Sigma-Aldrich). The specific fluorogenic substrate for CTSB, Z-Arg-Arg-AMC hydrochloride salt, was supplied by Bachem AG (Bubendorf, Switzerland). Human colorectal adenocarcinoma Caco-2 cells (ATCC ${ }^{\circledR} \mathrm{HTB}_{-37^{\mathrm{TM}}}$ ) and human colorectal carcinoma HCT 116 cells $\left(\right.$ ATCC $^{\circledR}$ CCL-247 ${ }^{\mathrm{TM}}$ ) were purchased from ATCC (Manassas, USA). Primary monoclonal IgG rat anti-human CTSB antibodies were purchased from R\&D Systems (Minneapolis, USA). Secondary IgG $(\mathrm{H}+\mathrm{L})$ goat anti rat antibodies conjugated with Alexa Fluor 633 dye were purchased from Invitrogen (Carlsbad, USA). All other reagents were of analytical, LC/MS or other grade suitable for cell culturing.

\section{Methods}

\section{Cell culture}

The human colorectal adenocarcinoma Caco-2 cells $\left(\mathrm{ATCC}{ }^{\circledR} \mathrm{HTB}-37^{\mathrm{TM}}\right.$ ) and human colorectal carcinoma HCT 116 cells (ATCC ${ }^{\circledR}$ CCL-247 $7^{\mathrm{TM}}$ ) were cultured at $37^{\circ} \mathrm{C}$ in $95 \%$ air with $5 \% \mathrm{CO}_{2}$ in CELCULTURE ${ }^{\circledR}$ CCL-170B-8 incubator (Esco, Singapore) with EMEM (Eagle's Minimum Essential Medium; BioWhittaker ${ }^{\circledR}$, Lonza, Basel, Switzerland), supplemented with $2 \mathrm{mmol} / \mathrm{L} \mathrm{L-glutamine,} 10 \%$ (v/v) fetal bovine serum (FBS), $100 \mathrm{U} / \mathrm{mL}$ penicillin, $100 \mu \mathrm{g} / \mathrm{mL}$ streptomycin, and $0.25 \mu \mathrm{g} / \mathrm{mL}$ amphotericin B (Gibco, Thermo Fisher Scientific). The medium was renewed every 3 days. Cells were harvested with TrypLE ${ }^{\mathrm{TM}}$ Express (Gibco, Thermo Fisher Scientific) after rinsing with Dulbecco's Phosphate Buffered Saline solution (DPBS; Gibco, Thermo Fisher Scientific). The cells were counted with Countess ${ }^{\mathrm{TM}}$ Automated Cell Counter (Invitrogen) after staining with $0.4 \%$ trypan blue solution (Invitrogen).

\section{Scratch/wound healing assay}

Seventy microliters of cell suspension containing $5 \times 10^{4}$ cells was added to each well of the two-well culture insert (Ibidi, Gräfelfing, Germany), placed into a 24-well cell culture plate and cultured for $24 \mathrm{~h}$. Subsequently, the inserts were removed from the wells and the wells were rinsed with DPBS, followed by the addition of EMEM with or without $10 \mu \mathrm{M}$ or $30 \mu \mathrm{M}$ of 3 -BrPA. The closure of the insert-created gap (wound, initially $500 \mu \mathrm{m}$ ) was observed after $0 \mathrm{~h}, 24 \mathrm{~h}$, and $48 \mathrm{~h}$ under a CKX41 inverted microscope with a SC30 camera (Olympus, Tokyo, Japan). The gap area was measured using the MRI Wound Healing Tool macro for Image software (National Institutes of Health, Bethesda, USA). 


\section{Cell invasion assay}

For cell invasiveness testing, the cells were cultured in standard conditions until $80 \%$ confluence was achieved; then, the medium was changed to EMEM 0\% FBS and the culture was incubated for $24 \mathrm{~h}$, followed by harvesting with TrypLE ${ }^{\mathrm{TM}}$ Express reagent and centrifugation in EMEM 5\% bovine serum albumin (BSA). The cell suspensions were diluted in EMEM 0\% FBS to a concentration of $5 \times 10^{5}$ cells $/ \mathrm{mL}$.

3-bromopyruvate in EMEM 0\% FBS was added (up to $50 \mu \mathrm{M}$ for Caco- 2 and up to $30 \mu \mathrm{M}$ for HCT 116) to the cell suspensions to obtain the concentration of the compound used in the experiment, while the controls were supplemented with the appropriate volume of EMEM 0\% FBS. The cell suspensions were gently placed on a $\mathrm{QCM}^{\mathrm{TM}}$ Cell Invasion Assay 96-well plate (Chemicon, Merck, Darmstadt, Germany) prepared according to the manufacturer's instructions, based on the Boyden chamber principle. The experiment was carried out according to the manufacturer's recommendations. The following controls were also performed for each cell line: cells without 3-BrPA and a medium without chemoattractant in the wells in which the insert was placed. Fluorescence was measured using a CLARIOstar $^{\circledR}$ (BMG Labtech, Offenburg, Germany) microplate reader with values of $\lambda e x=480 \mathrm{~nm}$ and $\lambda e m=520 \mathrm{~nm}$.

\section{Fluorescent microplate assay}

for cancer-cell-associated CTSB

The assay used in our study was a modified version of the method published by Hulkower et al. ${ }^{24}$ In brief, $5 \times 10^{4}$ Caco-2/HCT 116 cells per well were seeded into a 96 -well plate and cultured $\left(37^{\circ} \mathrm{C} ; 5 \% \mathrm{CO}_{2}\right)$ for $24 \mathrm{~h}$, then the medium was changed to EMEM 0\% FBS with or without 3-BrPA and incubated for $1 \mathrm{~h}$, after which the culture medium was replaced with a fresh one (0\% FBS). The culture was carried out for a further $24 \mathrm{~h}$ to obtain $80 \%$ confluence. The medium was then collected from the cell layer and identical volumes were transferred to empty wells on the plate. The cell layer was washed with sterile DPBS solution and then incubated for $30 \mathrm{~min}$ with pericellular assay buffer (PAB) I (Hank's Balanced Salt Solution) without sodium bicarbonate, $0.6 \mathrm{mM}$ of $\mathrm{CaCl}_{2}, 0.6 \mathrm{mM}$ of $\mathrm{MgCl}_{2}, 25 \mathrm{mM}$ of PIPES, and $2 \mathrm{mM}$ of L-cysteine ( $\mathrm{pH} 7.0)$ ) under the abovementioned conditions. After the incubation time, the PAB I was removed. Subsequently, PAB II (Hank's Balanced Salt Solution without sodium bicarbonate, $0.6 \mathrm{mM}$ of $\mathrm{CaCl}_{2}, 0.6 \mathrm{mM}$ of $\mathrm{MgCl}_{2}, 25 \mathrm{mM}$ of PIPES, and $2 \mathrm{mM}$ of L-cysteine (pH 7.0)) containing $100 \mathrm{mM}$ of Z-Arg-Arg-AMC substrate was added to the wells containing cells and previously collected post-culture media. In half of the wells containing cells, the composition of PAB II also included $0.1 \%$ aqueous solution of Triton X-100 in order to obtain the lysis effect of cell membranes, thereby visualizing the total cellular activity of CTSB. In the half of the wells with cells where the detergent was not added, the activity of CTSB at the cell surface was evaluated. Spectrofluorimetric evaluation of the reaction product gain per minute was performed on a CLARIOstar ${ }^{\mathbb{R}}$ microplate reader with values of $\lambda_{\mathrm{ex}}=380 \mathrm{~nm}$ and $\lambda_{\mathrm{em}}=460 \mathrm{~nm}$.

\section{Indirect immunofluorescence}

and flow cytometry analysis

Cells for flow cytometry analysis were seeded in sixwell plates at $1 \times 10^{6}$ cells per well under standard conditions. After obtaining $80 \%$ confluence, the medium was changed to EMEM 0\% FBS with $30 \mu \mathrm{M} 3$-BrPA (test samples) or EMEM 0\% FBS (control samples) for $1 \mathrm{~h}$. Subsequently, the medium was replaced with fresh EMEM 0\% FBS. The culture was carried out for $24 \mathrm{~h}$, followed by medium removal, mechanical culture harvesting in PBS $2 \%$ FBS, centrifugation, resuspension of cell pellets in PBS 2\% FBS, and centrifugation. The resulting pellets were suspended in PBS buffer with primary rat anti-human CTSB monoclonal antibodies at a concentration of $2.5 \mu \mathrm{g} / \mathrm{mL}$ and incubated for $30 \mathrm{~min}$ at room temperature. Afterwards, the suspensions were centrifuged, the pellets were washed with PBS, centrifuged again, resuspended in a PBS solution containing secondary goat anti rat IgG $(\mathrm{H}+\mathrm{L})$ antibodies conjugated with Alexa Fluor 633 dye (1:200 dilution ratio), and incubated in the dark for $30 \mathrm{~min}$, followed by 2 cycles of washing in PBS. The analysis of the results showing the presence of the antigen (CTSB) on the outer surface of the cell membrane was performed using a CytoFLEX flow cytometer (Beckman Coulter, Indianapolis, USA) equipped with CytExpert v. 2.1 software (Beckman Coulter). The fluorescence emission of used fluorochrome (Alexa Fluor 633) was evaluated (channel: FL6, laser: $635 \mathrm{~nm}$, wavelength: corresponding to allophycocyanin). The results were developed using Kaluza Analysis Software (Beckman Coulter) v. 2.0. The number of cells subjected to flow cytometry analysis differed between samples (due to the way they were prepared), so we present the data showing the relative fluorescence intensity of fluorochrome per cell, as a result of dividing the mean of relative fluorochrome fluorescence intensity of a given population by the number of cells present within it.

\section{Cathepsin B spectrofluorimetric enzymatic activity assay}

The assay used in our research was a modified version of the method published by Barrett. ${ }^{25}$ Samples consisting of $0.75 \mathrm{nM}$ of purified human liver CTSB, the desired concentrations of 3-BrPA, deionized water, reaction buffer I (0.4 $\mathrm{M}$ of phosphate buffer and $4 \mathrm{mM}$ of EDTA (pH 6.0)), and $0.1 \%$ Brij $35 \mathrm{P}$ were subjected to $10 \mathrm{~min}$ of preincubation at $37^{\circ} \mathrm{C}$. The enzyme reaction was started by adding 
$100 \mu \mathrm{M}$ of Z-Arg-Arg-AMC substrate in reaction buffer II (0.4 M of phosphate buffer, $8 \mathrm{mM}$ of L-cysteine, and $4 \mathrm{mM}$ of EDTA (pH 6.0)). The reaction was carried out at $37^{\circ} \mathrm{C}$ for $15 \mathrm{~min}$. Fluorescence was measured with a CLARI$\operatorname{Ostar}^{\circledR}$ (BMG Labtech) microplate reader at $\lambda_{\mathrm{ex}}=380 \mathrm{~nm}$ and $\lambda_{\mathrm{em}}=460 \mathrm{~nm}$.

\section{Zymography}

Samples consisting of $130 \mathrm{nM}$ of purified human liver CTSB (positive control) and 50-5000 $\mu \mathrm{M}$ of 3-BrPA were incubated for $10 \mathrm{~min}$ at $37^{\circ} \mathrm{C}$, after which the samples were electrophoresed on $8 \%$ lithium dodecyl sulfate (LDS) polyacrylamide gel containing $0.1 \%$ porcine skin gelatin. The buffering system and staining/destaining procedures followed the protocol described by Klose et al. ${ }^{26}$ The resulting zymogram was documented using Gel-Doc ${ }^{\mathrm{TM}}$ EZ (Bio-Rad, Hercules, USA) and the results were analyzed with Image Lab v. 5.2.1 (Bio-Rad).

\section{Liquid chromatography/mass spectrometry analysis}

The tested samples, consisting of $2 \mu \mathrm{M}$ of CTSB with $500 \mu \mathrm{M}$ of 3 -BrPA in $50 \mathrm{mM}$ of acetate buffer (with $1 \mathrm{mM}$ of EDTA; pH 5.0) and control samples ( $2 \mu \mathrm{M}$ of CTSB in $50 \mathrm{mM}$ of acetate buffer (with $1 \mathrm{mM}$ of EDTA; pH 5.0)) were incubated for $10 \mathrm{~min}$ at $37^{\circ} \mathrm{C}$ prior to separation. Mass spectrometric studies were conducted using a NanoAcquity UPLC Q-TOF/MS (Waters, Milford, USA) system. The chromatograph was equipped with an Acquity UPLC HSS C18 analytical column $(1 \mathrm{~mm} \times 100 \mathrm{~mm}$; $1.8 \mu \mathrm{m}$ ) with the flow-rate maintained at $50 \mu \mathrm{L} / \mathrm{min}$ and the injection volume at $3 \mu \mathrm{L}$. The separation was held for $15 \mathrm{~min}$ at $35^{\circ} \mathrm{C}$. The mobile phase constituents were solvent A $-0.1 \%$ formic acid in water - and solvent B, $0.1 \%$ formic acid in acetonitrile. The elution took place in a gradient system: $0-1 \mathrm{~min}: 15 \% \mathrm{~B} ; 2 \mathrm{~min}: 25 \% \mathrm{~B}$; 8 min: $60 \%$ B; 10 min: $85 \%$ B; 11 min: $85 \%$ B; 11.5 min: $15 \% \mathrm{~B} ; 15 \mathrm{~min}: 15 \% \mathrm{~B}$. The eluted CTSB was analyzed using Xevo G2-Q-TOF (Waters) mass spectrometer with an electrospray ionization source in positive ionization mode (ESI+). The capillary voltage was set at $3.0 \mathrm{kV}$, and the cone voltage for CTSB was set at $40 \mathrm{~V}$. The cone gas flow was maintained at $80 \mathrm{~L} / \mathrm{h}$, and the source temperature was set at $100^{\circ} \mathrm{C}$. Leucine Enkephalin (Waters) was used as the lock mass solution. Data was collected from $m / z 200$ to $m / z 2000$. The mass spectra were deconvoluted with MaxEnt 1 (Waters).

\section{Statistical analysis}

The results of the scratch/wound healing assay and zymography are a representative set of photographs from 1 of the 3 experiments conducted. The gap area ratios for scratch/wound healing assay were calculated using a comparison of 2 ratios (the ratio of a gap area at a given time point to the gap area at $0 \mathrm{~h}$ for treated cells, compared to the ratios of their untreated counterparts). The results of the cell invasiveness and proteolytic activity experiments are presented as a mean value \pm standard deviation (SD) of 3 independent experiments, analyzed using the ttest for one mean. A p-value $<0.05$ was considered statistically significant. Statistical analysis was conducted using MedCalc Statistical Software v. 19.2 (MedCalc Software Ltd, Ostend, Belgium).

\section{Results}

\section{Effect of 3-bromopyruvate on colon cancer cells and properties of CTSB from colon cancer cells}

\section{Cell motility}

A scratch/wound healing assay was used to evaluate the effect of 3-BrPA treatment on the migratory properties of Caco-2 and HCT 116 colon cancer cells. Stimulation with 3-BrPA visibly decreased the motility of cells from both of the studied cancer cell lines in a dose-dependent manner (Fig. 1).

\section{Cell invasiveness}

The cell invasion assay was used to evaluate the effect of 3-BrPA treatment on the invasiveness of Caco-2 and HCT 116 colon cancer cells. The Caco-2 cells (Fig. 2A), as a result of 3-bromopyruvate treatment, showed reduced levels of invasiveness compared to the untreated control cells $(10 \%$ FBS $)$ in a dose-dependent manner. Fifty microliters of 3-BrPA reduced the invasiveness of the tested cells by more than $60 \%$ in comparison to the untreated positive control samples. The HCT 116 cells (Fig. 2B) also showed decreased invasiveness, but the response was weaker than in the Caco- 2 cells, reaching up to $25 \%$ decreased invasion compared to the controls.

\section{Cathepsin B proteolytic activity in cells and post-culture media}

The fluorescent microplate assay for cancer-cell-associated CTSB was used to evaluate the effect of 3-BrPA on CTSB proteolytic activity in Caco-2 and HCT 116 colon cancer cells and post-culture media. In Caco-2 cells (Fig. 3A) the total cellular activity of CTSB decreased in a dose-dependent manner, reaching $76 \%$ and $66 \%$ of the control value for 3-BrPA concentrations of $10 \mu \mathrm{M}$ and $30 \mu \mathrm{M}$, respectively. The activity of CTSB in postculture media was also reduced, though it was similar for both 3-BrPA concentrations used, amounting to about 75\% of the control value. 3-bromopyruvate did not affect the total cellular activity of CTSB in HCT 116 cells (Fig. 3B): 

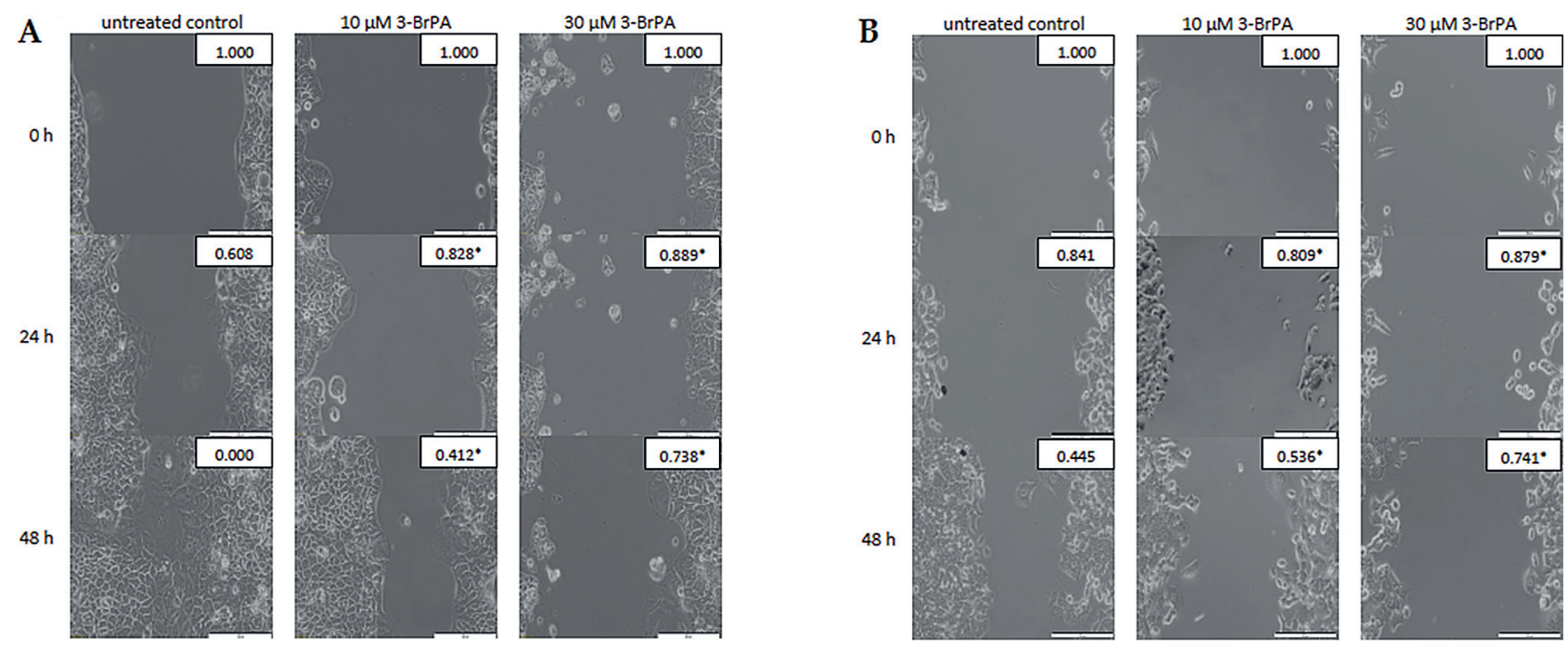

Fig. 1. The impact of one-hour 3-BrPA (10 $\mu \mathrm{M}$ and $30 \mu \mathrm{M})$ stimulation on the motility of Caco-2 (A) and HCT 116 (B) colon cancer cells at $0 \mathrm{~h}, 24 \mathrm{~h}$ and $48 \mathrm{~h}$ (representative data). Scale bars $(200 \mu \mathrm{m})$ appear in the lower right corner of each photograph; the numeric data in the upper right corner of each photograph indicates the gap area ratio at a given time point to the gap area at $0 \mathrm{~h}$. The ratios in treated cells significantly different $(p<0.05)$ from their untreated counterparts are marked with asterisks
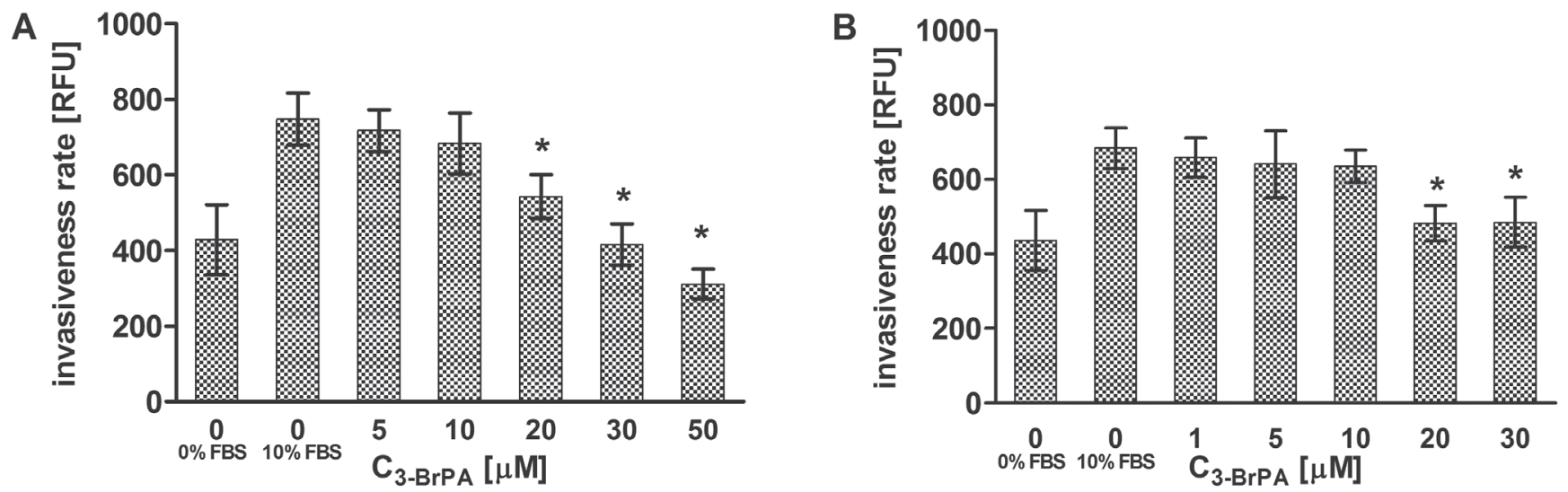

Fig. 2. The impact of 3-BrPA stimulation on the invasiveness of Caco-2 (A) and HCT 116 (B) colon cancer cells. Columns represent the level of cell invasiveness presented as mean fluorescence intensity of the CyQuant $G R^{\circledR}$ dye that stained (previously lysed) the invasive cells. The serum-free medium in the lower chamber was used as negative controls; 10\% FBS medium in the lower chamber was used as positive controls. Statistically significant differences $(p<0.05)$ in the treated cells compared to their respective controls are marked with asterisks

RFU - relative fluorescence units.
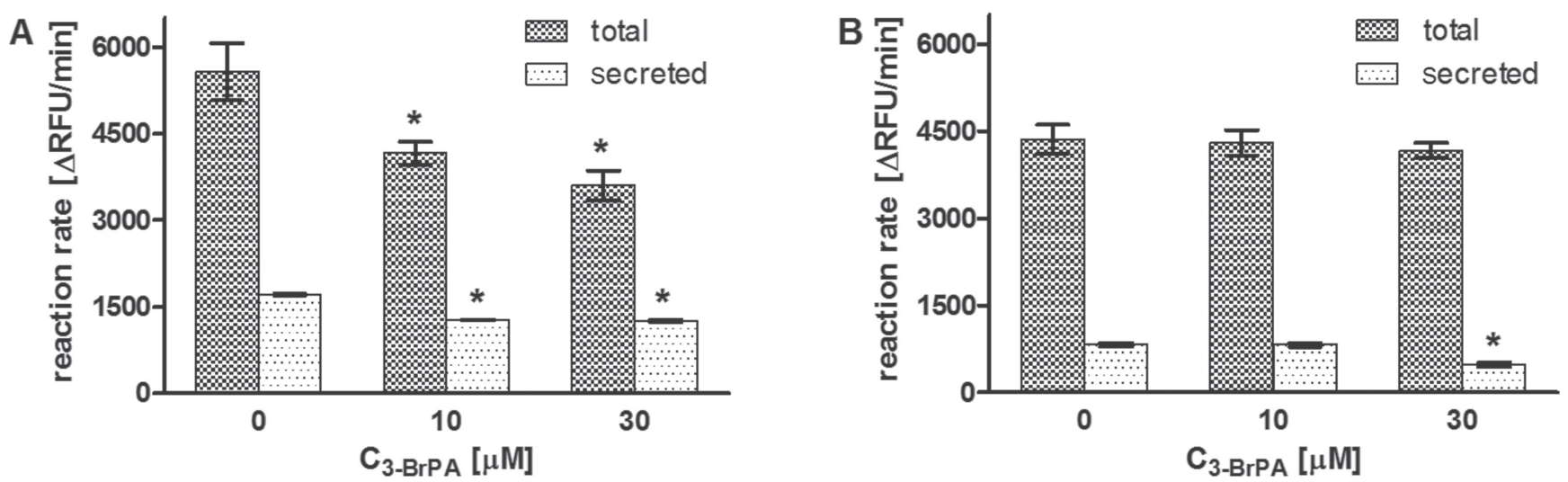

Fig. 3. The effect of 3-BrPA on proteolytic activity of CTSB in Caco-2 (A) and HCT 116 (B) colon cancer cells and post-culture media. Columns represent reaction rates (as a mean of 3 independent experiments \pm SD); statistically significant differences $(p<0.05)$ are marked with asterisks 
the fluorescence intensity values for the tested samples were about $96-98 \%$ of the control value for this parameter. However, a significant decrease in CTSB activity in HCT 116 post-culture media was observed in the $30-\mu \mathrm{M} 3-\mathrm{BrPA}$ samples. The activity decreased to about $58 \%$ of the control value. No measurable CTSB activity was detected on the cell surface.

\section{Cathepsin B exposure on surface of the outer membrane of the cells}

Indirect immunofluorescence and flow cytometry analysis was used to evaluate CTSB exposure on the surface of the outer membrane after 3-BrPA treatment. The results presented in Fig. 4 show that 3-BrPA treatment caused a considerable decrease CTSB exposure on the outer surface of the cell membrane in both of the examined colorectal cancer lines, but CTSB exposure in control cells and its loss in treated cells was much broader in Caco-2 cells.

\section{Effect of 3-bromopyruvate on properties of purified human CTSB}

\section{Proteolytic activity}

As shown in Fig. 5, 3-BrPA decreased the activity of CTSB in a dose-dependent manner, reaching $\mathrm{IC}_{50}$ at $750 \mu \mathrm{M}$; therefore, it cannot be considered a potent CTSB inhibitor.

\section{Type of inhibition}

The reversibility of CTSB inhibition by 3-BRPA was determined with gelatin zymography, in which CTSB aliquots were incubated with 3-BrPA prior to gel electrophoresis. The results shown in Fig. 6 indicate that 3-BrPA, irrespective of the concentration in the sample, dissociated from the molecule of the enzyme during migration in the gel, allowing cathepsin to restore its activity in the following stages of zymography. The bands on the zymogram representing the proteolytic activity of the tested samples against gelatin were comparable to the control. This result indicates that the inhibition of CTSB by $3-\mathrm{BrPA}$ is reversible.

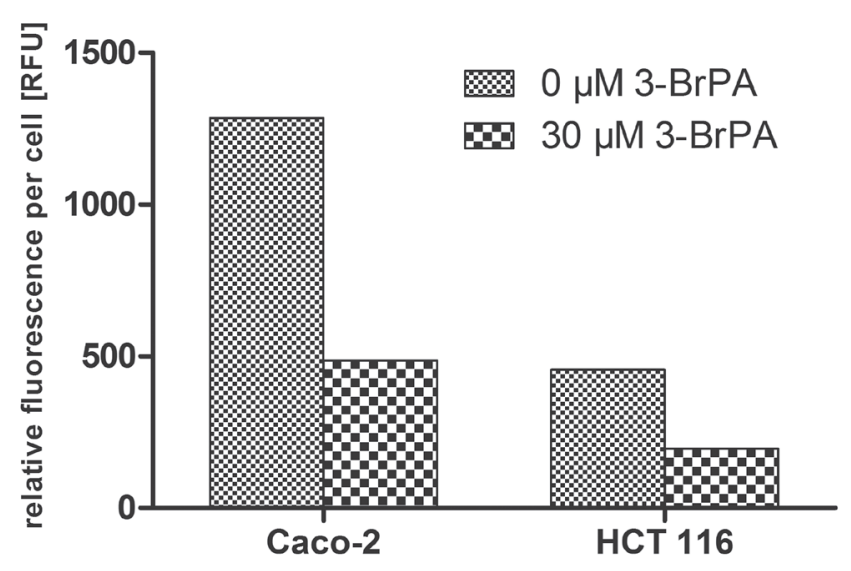

Fig. 4. The effect of 3-BrPA on CTSB exposure on the surface of the outer membrane of the cells in Caco-2 and HCT 116 colon cancer cells. Columns represent relative fluorescence of Alexa Fluor 633 dye per cell

RFU - relative fluorescence units.

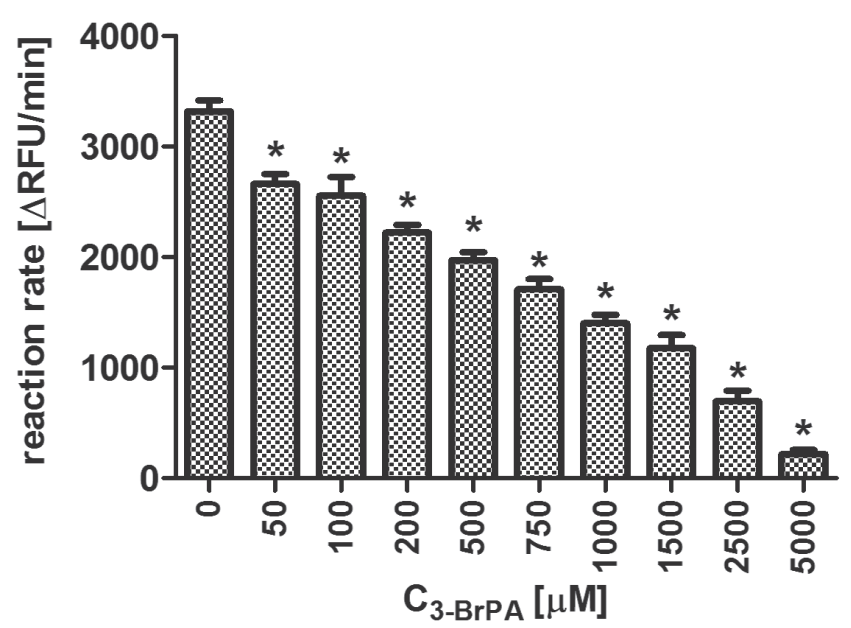

Fig. 5. The effect of 3-BrPA on purified human CTSB activity evaluated with spectrofluorimetric assay. Columns represent reaction rates (as a mean of 3 independent experiments $\pm \mathrm{SD}$ ); statistically significant differences $(p<0.05)$ are marked with asterisks

RFU - relative fluorescence units.

\section{Modifications of the protein molecule}

To confirm that 3-BrPA does not bind covalently to the molecule of CTSB, a liquid chromatography/mass spectrometry analysis was performed. As shown in Fig. 7,

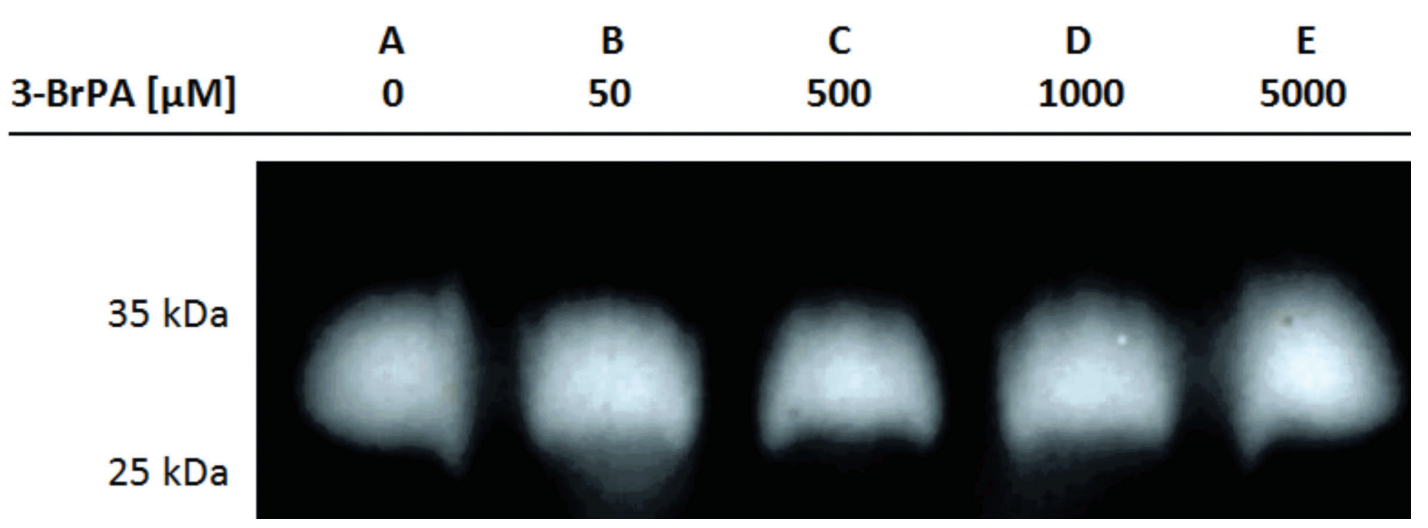

Fig. 6. Zymographic investigation of the reversibility of CTSB inhibition by 3-BrPA. Transparent bands represent CTSB activity of (A) positive controls (130 nM of CTSB) and (B-E) $130 \mathrm{nM}$ of CTSB incubated for $10 \mathrm{~min}$ at $37^{\circ} \mathrm{C}$ with 3-BrPA prior to electrophoresis 


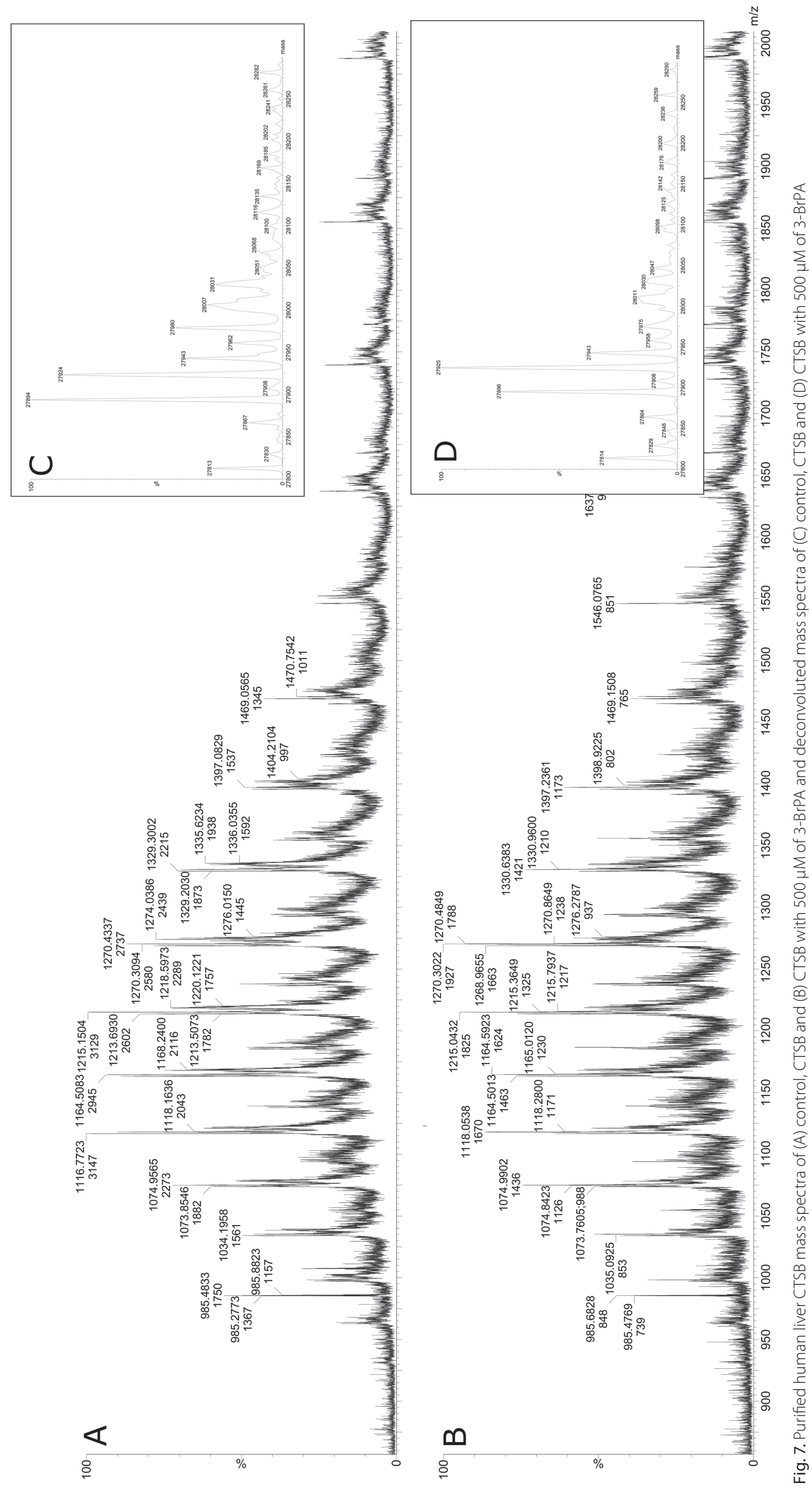


the mass spectrum of the test sample (Fig. 7B,D) and the mass spectrum of the control (Fig. 7A,C) showed no notable differences, a finding which proves a lack of covalent modifications within the CTSB molecule caused by 3-BrPA.

\section{Discussion}

Much of the research on the antitumor effects of 3-BrPA focuses on its alkylating action on the enzymes of the glycolytic pathway and the respiratory chain; therefore, we decided to look at this compound from a different perspective and examine how it affects the metastasis process by acting on the enzyme CTSB. Cell lines selected for the purposes of this study have been used in research on both $3-\mathrm{BrPA}^{27}$ and CTSB. ${ }^{12,24,28}$ Our studies based on cancer cell cultures included a one-hour incubation of cells with 3-BrPA. The choice of this incubation time was dictated by the halflife of 3-BrPA (about $77 \mathrm{~min}$ at a $\mathrm{pH}$ of $\sim 7^{29}$ ). The selected 3-BrPA concentrations in the experiments did not significantly decrease cell viability (checked with sulforhodamine B assay, data not shown). Being based on the above assumptions, the results cannot be compared with those of studies by Lea et al. and Ho et al., who used a 72-hour incubation time with 3-BrPA, obtaining $\mathrm{IC}_{50}$ values for this compound of $50 \mu \mathrm{M}^{27}$ and $37 \mu \mathrm{M}^{30}$ for the Caco- 2 cell line and $25 \mu \mathrm{M}^{27}$ and $23 \mu \mathrm{M}^{30}$ for the HCT 116 cell line. These studies reported lower sensitivity of the Caco-2 cells to 3-BrPA compared to HCT 116 cells. This may be due to a different baseline level of glutathione (GSH), the main cellular antioxidant, in both cell lines: higher in Caco-2 and lower in HCT $116 .{ }^{31} 3-\mathrm{BrPA}$ reduces the level of $\mathrm{GSH}^{32}$ and stimulates the production of free radicals, increasing oxidative stress in the cell..$^{33}$

Research presented by El Sayed et al., Xu et al. and Tomizawa et al. on the inhibitory effect of 3-BrPA on cell motility confirmed our observations, but these studies were carried out on human C6 glioma, ${ }^{34}$ U87 and CD133 + U87, ${ }^{35}$ and HCC hepatocellular carcinoma ${ }^{36}$ cell lines. The results from the invasiveness assay indicated an overall higher invasiveness of Caco-2 cells than the HCT 116 line and a greater susceptibility of the former to stimulating invasion in the presence of a chemoattractant $(10 \%$ FBS). As expected, both cell lines displayed decreased invasiveness after 3-BrPA treatment, with Caco-2 exhibiting a clearer effect dependent on the concentration of the compound. This effect may be caused by the inhibition of proteolytic enzymes by 3-BrPA - especially CTSB, which is responsible for the degradation of protein components present in the ECMatrix ${ }^{\mathrm{TM}}$ layer - and the effect of this compound on cellular mechanisms of synthesis and secretion of proteolytic enzymes. These assumptions have been confirmed by Bian et al., who proved with an analogous method that the treatment of colorectal cancer cells with CTSB-specific inhibitor CA-074 significantly reduces their invasiveness in vitro. A similar effect was observed after reducing CTSB expression in the tested cells. ${ }^{12}$
The tests on the proteolytic activity of CTSB in cells and post-culture media indicated a higher total activity of CTSB in the cells (determined after lysis of cell membranes with Triton X-100 detergent) and in post-culture media in the Caco- 2 cell line than in the HCT 116 cell line, which is in agreement with the results presented by Bian et al. ${ }^{12}$ The inhibitory effect of 3-BrPA on the total cellular activity of CTSB in a dose-dependent manner was visible only in Caco-2 cells, suggesting that this compound probably acts on the cellular mechanisms responsible for CTSB processing in those cells, in contrast to HCT 116. The negative effect of 3-BrPA on the secretion of CTSB was visible in both cell lines, suggesting that it may interfere with the intracellular distribution and secretion of this enzyme, in addition to the above effects. The mechanisms underlying these observations require further research. In the interpretation of results obtained with indirect immunofluorescence and flow cytometry analysis, we used fluorescence per cell as a parameter. It presents comparable values between 2 lines and between samples within a line. Our research demonstrated that the cells of both tested lines have CTSB on the outer surface of the cell membrane, which has been confirmed by the studies of both lines obtained by Hulkower et al. ${ }^{24}$ and of the HCT 116 line published by CavalloMedved et al. ${ }^{28} 3$-bromopyruvate, incubated with cells for $1 \mathrm{~h}$ on the day preceding the measurement, caused an average twofold decrease in CTSB exposure on the cell surface of both lines compared to the control cells, with a higher exposure for the Caco-2 line. These observations, supported by the spectrofluorimetric experiments described above, may suggest that 3-bromopyruvate affects the mechanisms of CTSB distribution and the interaction of this protein with the membrane in colorectal cancer cells. Studies on a cellular model did not provide an opportunity to reveal the mechanism of 3-BrPA action on the enzyme. Therefore, we conducted further experiments on the purified protein.

In our research, we used 2 enzymatic methods: spectrofluorimetry and gelatin zymography, which have been successfully applied for CTSB enzymatic activity evaluation. ${ }^{37}$ The relatively high concentrations of 3-BrPA inhibiting CTSB activity, particularly in comparison with the concentrations of irreversible inhibitors of this enzyme presented in an article by Frlan and Gobec, ${ }^{18}$ raised our concerns as to the validity of attributing the effects of 3-BrPA-CTSB interaction to its alkylating effect and, consequently, also the question of reversing this inhibition. The analysis of the zymogram produced in this study indicated that the inhibition of CTSB by 3-BrPA would be reversible. During the electrophoresis process, 3-BrPA dissociated from the enzyme molecule, allowing CTSB to restore its activity in subsequent stages of zymography. Such an effect would not be possible if there was an alkylation reaction between these molecules (in which the inhibitor covalently binds to the enzyme). We confirmed this observation by mass spectrometry/liquid chromatography analysis, as the increase in molecular weight expected in the case 
of 3-BrPA-mediated alkylation should amount $+86 \mathrm{Da}$, and the mass spectra of CTSB and CTSB incubated with 3 -BrPA in our study showed no such differences. Although detailed mechanisms of the interaction between 3-BrPA and CTSB require further research, these results provide a new perspective from which to study the antitumor and antimetastatic effect of 3-BrPA.

\section{ORCID iDs}

Izabela Szczuka (1) https://orcid.org/0000-0001-7311-9633 Jerzy Wiśniewski (1) https://orcid.org/0000-0003-2831-7643 Irena Kustrzeba-Wójcicka (1) https://orcid.org/0000-0001-5551-4445 Grzegorz Terlecki (1) https://orcid.org/0000-0001-8242-0866

\section{References}

1. Turk V, Turk B, TurkD. Lysosomal cysteine proteases: Facts and opportunities. EMBO J. 2001;20(17):4629-4633. doi:10.1093/emboj/20.17.4629

2. Gondi CS, Rao JS. Cathepsin B as a cancer target. Expert Opin Ther Targets. 2013;17(3):281-291. doi:10.1517/14728222.2013.740461

3. Mohamed MM, Sloane BF. Cysteine cathepsins: Multifunctional enzymes in cancer. Nat Rev Cancer. 2006;6(10):764-775. doi:10.1038/nrc1949

4. Koblinski JE, Ahram M, Sloane BF. Unraveling the role of proteases in cancer. Clin Chim Acta. 2000;291(2):113-135. doi:10.1016/S00098981(99)00224-7

5. Kostoulas G, Lang A, Nagase H, Baici A. Stimulation of angiogenesis through cathepsin $B$ inactivation of the tissue inhibitors of matrix metalloproteinases. FEBS Lett. 1999;455(3):286-290. doi:10.1016/ S0014-5793(99)00897-2

6. Musil D, Zucic D, Turk D, et al. The refined 2.15 A X-ray crystal structure of human liver cathepsin B: The structural basis for its specificity. EMBO J. 1991;10(9):2321-2330.

7. Aggarwal N, Sloane BF. Cathepsin B: Multiple roles in cancer. Proteomics Clin Appl. 2014;8(5-6):427-437. doi:10.1002/prca.201300105

8. li K, Ito H, Kominami E, Hirano A. Abnormal distribution of cathepsin proteinases and endogenous inhibitors (cystatins) in the hippocampus of patients with Alzheimer's disease, parkinsonism-dementia complex on Guam, and senile dementia and in the aged. Virchows Arch A Pathol Anat Histopathol. 1993;423(3):185-194. doi:10.1007/ BF01614769

9. Nagai A, Murakawa $Y$, Terashima $M$, et al. Cystatin $C$ and cathepsin $B$ in CSF from patients with inflammatory neurologic diseases. Neurology. 2000;55(12):1828-1832. doi:10.1212/WNL.55.12.1828

10. Mitrović A, Mirković B, Sosič I, Gobec S, Kos J. Inhibition of endopeptidase and exopeptidase activity of cathepsin B impairs extracellular matrix degradation and tumour invasion. Biol Chem. 2016;397(2):165174. doi:10.1515/hsz-2015-0236

11. Abdulla MH, Valli-Mohammed MA, Al-Khayal K, et al. Cathepsin B expression in colorectal cancer in a Middle East population: Potential value as a tumor biomarker for late disease stages. Oncol Rep. 2017. doi:10.3892/or.2017.5576

12. Bian B, Mongrain S, Cagnol S, et al. Cathepsin B promotes colorectal tumorigenesis, cell invasion, and metastasis. Mol Carcinog. 2016;55(5):671-687. doi:10.1002/mc.22312

13. Hazen LGM, Bleeker FE, Lauritzen B, et al. Comparative localization of cathepsin B protein and activity in colorectal cancer. J Histochem Cytochem. 2000;48(10):1421-1430. doi:10.1177/002215540004801012

14. Campo E, Muñoz J, Miquel R, et al. Cathepsin B expression in colorectal carcinomas correlates with tumor progression and shortened patient survival. Am J Pathol. 1994;145(2):301-309.

15. Hirano T, Manabe T, Takeuchi S. Serum cathepsin B levels and urinary excretion of cathepsin B in the cancer patients with remote metastasis. Cancer Lett. 1993;70(1):41-44. doi:10.1016/0304-3835(93)90072-H

16. Hirai K, Yokoyama M, Asano G, Tanaka S. Expression of cathepsin B and cystatin C in human colorectal cancer. Hum Pathol. 1999;30(6):680686. doi:10.1016/S0046-8177(99)90094-1

17. Van Noorden CJF, Jonges TGN, Van Marle J, et al. Heterogeneous suppression of experimentally induced colon cancer metastasis in rat liver lobes by inhibition of extracellular cathepsin B. Clin Exp Metastasis. 1998;16(2):159-167. doi:10.1023/A:1006524321335
18. Frlan R, Gobec S. Inhibitors of cathepsin B. Curr Med Chem. 2006; 13(19):2309-2327. doi:10.2174/092986706777935122

19. Birsoy K, Wang T, Possemato R, et al. MCT1-mediated transport of a toxic molecule is an effective strategy for targeting glycolytic tumors. Nat Genet. 2013;45(1):104-108. doi:10.1038/ng.2471

20. Cardaci S, Desideri E, Ciriolo MR. Targeting aerobic glycolysis: 3-bromopyruvate as a promising anticancer drug. J Bioenerg Biomembr. 2012;44(1):17-29. doi:10.1007/s10863-012-9422-7

21. Shoshan MC. 3-bromopyruvate: Targets and outcomes. J Bioenerg Biomembr. 2012;44(1):7-15. doi:10.1007/s10863-012-9419-2

22. El Sayed SM, Mohamed WG, Hassan Seddik MA, et al. Safety and outcome of treatment of metastatic melanoma using 3-bromopyruvate: A concise literature review and case study. Chin J Cancer. 2014;33(7):356-364. doi:10.5732/cjc.013.10111

23. Ko YH, Verhoeven HA, Lee MJ, Corbin DJ, Vogl TJ, Pedersen PL. A translational study "case report" on the small molecule "energy blocker" 3-bromopyruvate (3BP) as a potent anticancer agent: From bench side to bedside. J Bioenerg Biomembr. 2012;44(1):163-170. doi:10.1007/s10863-012-9417-4

24. Hulkower KI, Butler CC, Linebaugh BE, et al. Fluorescent microplate assay for cancer cell-associated cathepsin B. Eur J Biochem. 2000;267(13):4165-4170. doi:10.1046/j.1432-1327.2000.01458.x

25. Barrett AJ. Fluorimetric assays for cathepsin B and cathepsin $\mathrm{H}$ with methylcoumarylamide substrates. Biochem J. 1980;187(3):909-912. doi:10.1042/bj1870909

26. Klose A, Zigrino P, Dennhöfer R, Mauch C, Hunzelmann N. Identification and discrimination of extracellularly active cathepsins $B$ and $L$ in high-invasive melanoma cells. Anal Biochem. 2006;353(1):57-62. doi:10.1016/j.ab.2006.01.037

27. Lea MA, Qureshi MS, Buxhoeveden M, Gengel N, Kleinschmit J, Desbordes C. Regulation of the proliferation of colon cancer cells by compounds that affect glycolysis, including 3-bromopyruvate, 2-deoxyglucose and biguanides. Anticancer Res. 2013;33(2):401-407.

28. Cavallo-Medved D, Rudy D, Blum G, Bogyo M, Caglic D, Sloane BF. Live-cell imaging demonstrates extracellular matrix degradation in association with active cathepsin B in caveolae of endothelial cells during tube formation. Exp Cell Res. 2009;315(7):1234-1246. doi:10.1016/j.yexcr.2009.01.021

29. Glick M, Biddle P, Jantzi J, Weaver S, Schirch D. The antitumor agent 3-bromopyruvate has a short half-life at physiological conditions. Biochem Biophys Res Commun. 2014;452(1):170-173. doi:10.1016/j. bbrc.2014.08.066

30. Ho N, Morrison J, Silva A, Coomber BL. The effect of 3-bromopyruvate on human colorectal cancer cells is dependent on glucose concentration butnothexokinase ll expression.BiosciRep. 2016;36(1):e00299. doi:10.1042/ BSR20150267

31. Kim AD, Zhang R, Han X, et al. Involvement of glutathione and glutathione metabolizing enzymes in human colorectal cancer cell lines and tissues. Mol Med Rep. 2015;12(3):4314-4319.. doi:10.3892/ mmr.2015.3902

32. Qin JZ, Xin H, Nickoloff BJ. 3-bromopyruvate induces necrotic cell death in sensitive melanoma cell lines. Biochem Biophys Res Commun. 2010;396(2):495-500. doi:10.1016/j.bbrc.2010.04.126

33. Kim JS, Ahn KJ, Kim JA, et al. Role of reactive oxygen species-mediated mitochondrial dysregulation in 3-bromopyruvate induced cell death in hepatoma cells: RROS-mediated cell death by 3-BrPA. J Bioenerg Biomembr. 2008;40(6):607-618. doi:10.1007/s10863-0089188-0

34. El Sayed SM, El-Magd RMA, Shishido Y, et al. 3-bromopyruvate antagonizes effects of lactate and pyruvate, synergizes with citrate and exerts novel anti-glioma effects. J Bioenerg Biomembr. 2012;44(1): 61-79. doi:10.1007/s10863-012-9409-4

35. Xu DQ, Tan XY, Zhang BW, et al. 3-bromopyruvate inhibits cell proliferation and induces apoptosis in CD133+ population in human glioma. Tumor Biol. 2016;37(3):3543-3548. doi:10.1007/s13277-015-3884-2

36. Tomizawa M, Shinozaki F, Motoyoshi Y, Sugiyama T, Yamamoto S, Ishige N. Suppressive effects of 3-bromopyruvate on the proliferation and the motility of hepatocellular carcinoma cells. Oncol Rep. 2016;35(1):59-63. doi:10.3892/or.2015.4370

37. Kędzior M, Seredyński R, Godzik U, et al. Inhibition of cathepsin B activity by 2,3,7,8-tetrachlorodibenzo-p-dioxin. Environ Sci Pollut Res. 2015;22(1):721-732. doi:10.1007/s11356-014-3482-7 